\title{
Breeding the oil palm (Elaeis guineensis Jacq.) for climate change
}

\author{
Alain Rival* \\ Cirad, DGD-RS, DRASEI, 12730 Jakarta, Indonesia \\ Received 19 December 2016 - Accepted 3 January 2017
}

\begin{abstract}
Breeding the oil palm (Elaeis guineensis Jacq.) for climate change requires multidisciplinary and collaborative research by nature: indeed - besides genetics and structural and functional genomics - almost all disciplines related to life sciences are involved. Research work also relies on the identification of genetic variation in the strategies of response to stress developed by the plant: this implies the exploration of resources provided by natural variation, germplasm collections, selected genitors from breeding programs together with material of interest collected from smallholders. The phenotyping of selected plant material under biotic/abiotic stress will involve new methods for high-throughput phenotyping and genomic approaches will be followed for the identification of genes underlying the variation of traits which will be used as selection targets. Also, improvements in understanding how climate change may influence chemical and physical processes in soils, how this may affect nutrient availability, and how the plant responds to changed availability of nutrients will also influence oil palm breeding programs. Molecular approaches and tools have great potential to optimize patterns of plant breeding, especially for perennial species. In recent years, there has been an exponential increase in molecular resources and methods aimed at identifying polymorphisms which control the traits of interest and exploring the mechanisms linking these polymorphisms to phenotypes. With genomic resources becoming increasingly available for the oil palm (sequencing, resequencing and chips development) the exploration of the genetic basis of complex traits such as oil yield or resistance to disease is now possible. Consequently the availability and sharing of such a large amount of data is currently reshaping most of oil palm breeding strategies.
\end{abstract}

Keywords: adaptability / drought / genomics / phenotyping / plasticity / polymorphism / sex ratio

\begin{abstract}
Résumé - Sélection génétique du palmier à l'huile ( Elaeis guineensis Jacq. ) et changement climatique. La sélection génétique du palmier à huile pour faire face au changement climatique exige par nature une recherche pluridisciplinaire et collaborative : en effet, outre la génétique et la génomique structurelle et fonctionnelle, presque toutes les disciplines liées aux sciences de la vie sont impliquées. Ce travail de recherche intégratif nécessite également de pouvoir estimer la variation génétique dans les processus de réponse au stress développés par les plantes: il implique une exploration des ressources offertes par la variation génétique naturelle, les collections de germoplasme, les meilleurs géniteurs issus des programmes de sélection, ainsi que par le matériel d'intérêt recueilli auprès des petits exploitants. Le phénotypage du matériel végétal sélectionné sous stress biotique ou abiotique va impliquer de nouvelles méthodes de phénotypage à haut débit et des approches génomiques devront être suivies pour l'identification des gènes à la source de variations dans des caractères qui vont devenir autant de cibles de sélection. Mieux comprendre la manière dont le changement climatique intervient sur les processus chimiques et physiques dans les sols, sur la disponibilité en éléments nutritifs et sur la réponse adaptée des plantes à cette disponibilité va permettre de recadrer les stratégies d'amélioration génétique du palmier à huile. Les approches et outils moléculaires ont un grand potentiel pour optimiser les modèles de sélection végétale, en particulier pour les espèces pérennes. Ces dernières années ont vu une augmentation exponentielle des ressources moléculaires et des méthodes pour identifier les polymorphismes contrôlant les caractères d'intérêt et destinées à explorer les mécanismes reliant ces polymorphismes à des phénotypes. Avec l'augmentation des ressources génomiques disponibles pour le palmier à huile (séquençage, re-séquençage, développement de puces), l'exploration de la base génétique de caractères complexes tels que le rendement ou la résistance aux maladies est maintenant possible. Par conséquent, la disponibilité et le partage d'un tel flot de données sont en train de modifier en profondeur la plupart des stratégies d'amélioration du palmier à huile.
\end{abstract}

Mots clés : adaptabilité / génomique / phénotypage / plasticité / polymorphisme / sécheresse / sex ratio

\footnotetext{
* Correspondence: alain.rival@cirad.fr
} 


\section{Introduction}

The large-scale cultivation of the oil palm (Elaeis guineensis Jacq.) has been able to drastically transform tropical landscapes and livelihoods in the recent decades (Rival and Levang, 2014). This outstanding crop produces very high oil yields and it shows an amazing agronomic plasticity: these are valuable assets in a context of climate change and ecological intensification. The sustainable development of oil palm cultivation is generating a series of questions to research, not only in the traditional domains of plant science, but also in the fields of socio-economy and social and human sciences (Rival and Jaligot, 2010; Rival, 2013; Rival et al., 2016).

Breeding for climate change requires by nature multidisciplinary actions (Hospes et al., 2017): indeed, almost all disciplines related to life sciences are involved, besides genetics and structural and functional genomics, namely: physiology, eco-physiology, biochemistry, developmental and cellular biology, agronomy, plant pathology, entomology, architectural modelling and data integration, etc.

The pivotal question is indeed to stabilize or - even better increase palm oil production under constraints brought by climate change. Such constraints will impact the environment of the current cultivated areas and/or induce the extension of plantations to new areas. It will also challenge the capacity for adaptation of various oil palm cropping systems (industrial estates and smallholders). Climate-related constraints will consequently shape the panel of oil palm ideotypes targeted by undergoing and future breeding programs. As for many other crops, climate change will impact the conditions of oil palm cultivation through a range of expected abiotic (amount and repartition of rainfall, temperatures, carbon dioxide concentration, soil salinity) and biotic (diseases, pests, pollinators, associated crops) stresses.

To be accurate enough, the setting of breeding targets must rely on a series of multidisciplinary analyses aimed at understanding the behaviour of the plant when cultivated under constraints, such as integrative analyses (ecophysiology, physiology and all -omics) performed at various degrees of organization (population, whole plant, organ, cell) or analyses of combined stresses under realistic scenario (e.g. high temperature + water deficit + limited solar radiation). Figure 1 illustrates a simplified strategy for integrative research aimed at orientating breeding for climate change. Modelling approaches will also be of great help for the definition of ideotypes and cropping systems which will have to be adapted to different climate change scenario.

In parallel, attention must be paid to the oil palm response to the occurrence and spread of pest and diseases (epidemiology) on the one hand and to changes in patho-systems (phytopathology) on the other hand. Indeed, Paterson et al. (2013) anticipated that land will become increasingly unsuitable for growing oil palm and the plants will become more stressed, thus allowing the ingress of fungal diseases.

With climate change, new land will become increasingly suitable for oil palm cultivation under environmental conditions which might be less drastic than tropical ones although with a risk that novel disease may threaten the crop.

Breeding for climate change also requires the identification of genetic variation in the processes of response to stress. This implies the exploration of resources offered by selected genitors from breeding programs, genetic tests, germplasm collections, material collected from smallholders and natural variation (Barcelos et al., 2015). The phenotyping of selected plant material under biotic/abiotic stress will involve new methods for high-throughput phenotyping and genomic approaches will be followed for the identification of genes underlying the variation of selection targets.

A combination of statistical modelling in genetics and ecophysiological modelling (architectural structure-function, mechanistic modelling) will be needed in order to predict the performance of genotypes of interest which could not be observed under modified environments.

High fertiliser use conflicts with the requirement to lower the emissions of greenhouse gases in fertiliser manufacturing, transportation and application, so improvements will be required in the nutrients uptake efficiency by breeding for suitable root systems. A remobilization of nitrogen and micronutrients within the plants will be required. Prolonged root uptake and better remobilization of nutrients are targets for breeding, provided there is sufficient plasticity of these characteristics in the oil palm for increases in efficiency to be achieved (Ollivier et al., 2016). Planters (either smallholders or large estates) are seeking planting material adapted to the climatic conditions surrounding their fields thus breeders' responses need to be adapted as well.

Pollination efficiency is critical as changing climatic conditions directly affect the activity of pollinator insect Elaedobius kameronicus (Mariau et al., 1991; Barfod et al., 2011). Besides, the availability of pollen is also a pivotal parameter as the feminization of planting material as a result of decades of breeding for oil yields makes it more sensitive to pollen availability. Breeding for super-male palms is under way in order to naturally provide a sufficient amount of pollen to high yielding varieties with elevated sex-ratio. Agricultural practices will also have a role to play as traditional cover crop such as Mucuna brachiata might not be the most appropriate one under severe drought conditions (Ollivier J., pers. com.).

\section{Breeding for integrated pest management}

It is of paramount importance to explore the genetic determinisms governing tolerance to major diseases. Indeed, the oil palm is susceptible to three rather specific diseases in each of the three continents where it is cultivated. In Africa, vascular wilt, caused by Fusarium oxysporum elaeidis, is still present and it can cause up to $70 \%$ mortality. In Southeast Asia, Ganoderma boninense has been found to cause up to $80 \%$ mortality in some regions. Lastly, in Latin America, a bud rot disease of yet unknown origin (although Phytophotra is a prime suspect) can be responsible of $100 \%$ losses in Elaeis guineensis plantations (Cochard et al., 2005). For these three rather endemic affections, genetic control strategies are being developed: indeed, the improvement of oil palm for tolerance is based on field observation of the sensitivity of parental material and their crosses and, where possible, on the assessment of the tolerance of each cross of interest through inoculation of the disease at pre-nursery stage. This process is very long and uncertain as to the genetic value of the parents and to relationship between controlled inoculation and natural 
CLIMATE-RELATED

BIOTIC + ABIOTIC STRESS

GENETICRESSOURCES

GENETIC TRIALS

COMMERCIAL VARIETIES

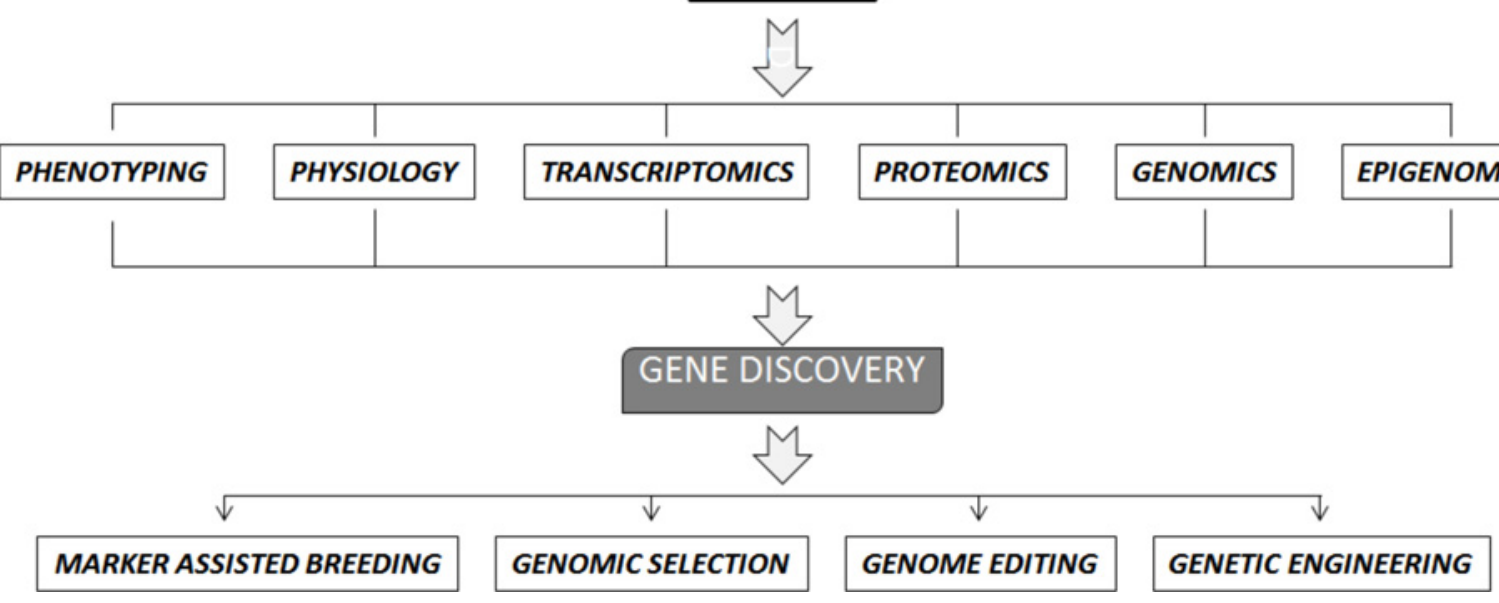

Fig. 1. A simplified strategy for integrative research aimed at implementing oil palm breeding for climate change.

infection in the field remains to be assessed on a case-by-case basis. However, the data already generated and currently being processed allowed the implementation of quantitative genetic analyses in order to explore the genetic determinisms of oil palm tolerance to these three major diseases. QTL research is being implemented for Fusarium wilt tolerance through the pre-nursery inoculation of a large mapping population, while testing for Ganoderma tolerance is based on a multi-parental genetic trial involving 14 families evaluated in the field in Indonesia for 25 years. In Latin America, Bud Rot resistance is assessed on first- and second-generation interspecific backcross planted in zones severely affected by the disease. The identification of genetic determinisms by appropriate methods will allow (i) to identify candidate genes on the basis of variation in disease tolerance within the species; (ii) to elucidate the key processes of tolerance - from the gene to the phenotype - through cross-checking between different diseases and between nursery tests and natural conditions and (iii) to implement marker-assisted selection for the fast and relevant integration of resistance sources into elite genotypes.

In order to process field data obtained in natural conditions of infection, analyses are based on epidemiological models coupled with genetic models, such as QTL or GWAS, or Bulk Segregant Analysis. When the disease is very aggressive, the use of early tests at pre-nursery stage requires preliminary analyses before being implemented. In both cases, the genetic mapping approach will be coupled with transcriptomic studies on crosses identified as sensitive or resistant in order to identify genes which are differentially expressed in the course of infection and between susceptible and resistant material. The combination of the two approaches will enable the identification of candidate genes as a basis for functional and diversity studies in the aim of involving such genes them in a markerassisted selection scheme (Fig. 1).

\section{Phenotypic plasticity and adaptation to agro-climatic constraints}

At present, breeding programs aimed at the genetic improvement of the oil palm focus on the generation of planting material able at outstandingly performing under all types of environments. Thus most genetic trials are multi-local thus favoring the potential for performance in the most favourable environment and differences in behaviour between environments are neglected in order to focus on average performance (Cochard et al., 2005). However, in practice, the use of planting material originating from various different backgrounds is recommended as a response to the environmental conditions encountered, most often on the basis of empirical observations. Following a multidisciplinary approach, it is important to understand the determinisms and the diversity of the mechanisms of response to environmental constraints in the oil palm, in order to better know the mechanisms of its adaptation. On the long term it will be then possible to define tolerant ideotypes and to set up new 
site-specific breeding schemes which will take into account the constraints of a given environment. It will also be necessary to pay attention to the different means and resources used among smallholders and large estates. Indeed, the more artificial the system (non-limiting fertilizer and water supplementation) the more the material used can approach the climatic potential of the crop (Cochard et al., 2005). On the other hand, the less the environment is controlled, the more the planting material must display rusticity characteristics, i.e. a capacity to adapt to various constraining situations and ensure a stable production.

Phenotypic plasticity refers to the expression of different phenotypes from the same genotype depending on environmental conditions. Phenotype expression can be measured at different levels of organization (cellular, tissue, organ, whole plant, block, etc.) and it translates genetic determinisms at different levels of expression and control (genetic, epigenetic, transcriptional, biochemical/metabolic, physiological, etc.). Thus, the study of phenotypic plasticity requires a wide variety of phenotyping approaches and specific skills to be mobilized for analytical experiments.

Phenotypic plasticity is both the expression and a source of adaptation, bringing together all the mechanisms and processes mobilized in the short/medium term response to a modification of environmental conditions. Some of the structural or functional changes thus induced are potentially inheritable and can be targeted directly by breders in order to create genotypes adapted or tolerant to a constraint or a set of constraints.

The evaluation of new palm morphotypes and the search for ideotypes will also depend on how the palm architecture governs the interception of light and the captation of carbon (Perez et al., 2016). This question is complex as it involves oil palm cultivation systems and climate, together with growth patterns of the palms and their physiology. The answers must therefore be adapted to the sites selected for field research work and their climatic conditions. Ultimately, the aim is to define the genotypes adapted to local conditions and to provide a basis for the selection of ideotypes carrying the best combination of architectural and functional traits. Such studies involve the modelling of the architecture of several genotypes on the same site and the further comparison of their efficiency for light interception (Perez et al., 2016). In this aim, the most important architectural features in interception efficiency must be identified and virtual palm architecture will be assessed while combining various architectural features in order to determine the most efficient ideotypes in terms of carbon captation. This research work will be complemented by the search for heritability of the identified traits, possibly coupled with a genomic study.

\section{Breeding for improved mineral nutrition under climate change conditions}

Improvements in understanding how climate change may influence chemical and physical processes in soils, how this may affect nutrient availability, and how the plant responds to changed availability of nutrients will influence oil palm breeding programs. The effects of increased atmospheric $\mathrm{CO}_{2}$ and warmer temperatures - both individually and combined on soil microbial activity, including mycorrhizas and $\mathrm{N}$-fixing

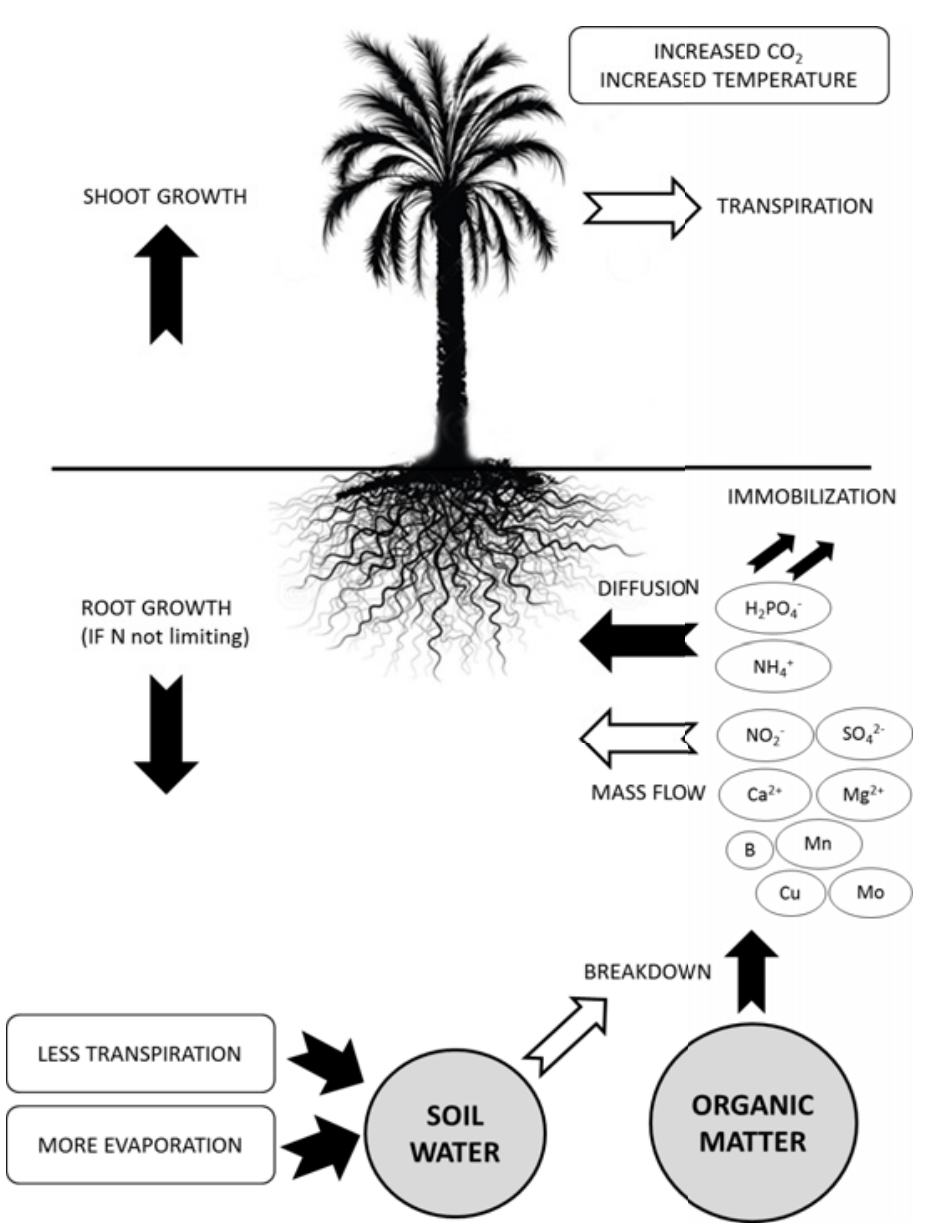

Fig. 2. Predicted effects of climate change on nutrient availability and plant growth. Variables affected by climate change are shown in boxes, and soil pools in circles. Decreases or increases in rainfall with climate change (dependent on geographic location) will interact with the effects of transpiration and evaporation on soil water pools. Mycorrhizal infection may increase with warmer temperatures, and lower effects of $\mathrm{N}$ and $\mathrm{P}$ limitation in nutrient-poor soils (adapted from Pilbeam, 2015).

organisms will change together with their implications for nutrient availability (Carron et al., 2015; Pardon et al., 2016). Potential changes to plant growth, and the combined effects of soil and plant changes on nutrient uptake are currently explored (Fig. 2). The implementation of research work on the efficient use of macro- and micronutrients by crops under climate change conditions is of paramount importance for the reshaping of plant breeding strategies, including analysis of QTLs for nutrient efficiency.

Climatic changes must now be taken into account through Genotype $\times$ Environment studies in particular to predict whether genetic materials are capable of preserving their production potential. For example, which oil palm planting material will be still productive under the $600 \mathrm{ppm}$ of $\mathrm{CO}_{2}$ anticipated for 2100 ? Also, a strong challenge will be to successfully plant oil palm in areas that will not be the most favourable any more while preserving regions harbouring valuable biodiversity. Under Genotype $\times$ Environment trials, the Genetics $\times$ Mineral Nutrition interaction is being considered (Ollivier et al., 2016). 
Fertilization of the oil palm is currently based on leaf analyses, which have been designed to adjust application rates to the level which is strictly necessary, thereby matching production requirements to both socio-economic and environmental conditions. Indeed, differences in susceptibility have been found between progenies and between clones for different minerals (Cochard et al., 2005; Ollivier et al., 2016). However, whether those differences in behaviour reflect different needs remains to be demonstrated. In the case of oil palm, there are technical constraints when defining fertilizers which depend on the germplasm involved. Studying fertilization requirements while taking regional specificities into account would probably mean setting up unrealistic trials. At the moment, given the selection methods used, seeking a fertilization program adapted to a genotype can only be undertaken using the commercially available planting material, running the risk of defining fertilizers adapted to material that is set to become obsolete. A more appropriate strategy would be to implement studies for the early assessment of nutritional requirements involving high throughput approaches (see Fig. 1).

The management of fertilization mostly depends on the empirical interpretation of indicators based on mineral analyses; other methods exist which are based on soil-plant balances, element by element, although to date neither method proved entirely satisfactory. Progress in the precise assessment of palm requirements will only be possible by improving our understanding of the flow of elements in the plant and their role in building oil yield. Recent ecophysiological approaches of nutrition trials have demonstrated strong interactions between mineral allocations and production-related metabolism. More prospectively, links between the transcriptomic expressions concerning the conversion of sugars to lipids and certain metabolic levers responsible for the filling of fruits under the influence of mineral intake can be established thanks to in depth investigations of the "metabolomic" and "isotopic" type ("Environmental" influences and those related to plant material to be identified and taken into account).

Lamade et al. (2016) generated an allocation pattern in oil palm based on observed $\delta^{13} \mathrm{C}$ values. Such a pattern does not rely on biomass distribution (except for the estimate of respiratory fractionation) and therefore is not biomass-based but rather reflects effective carbon fluxes and utilization. The allocation values are consistent with known carbon requirements and suggest a particularly high $\mathrm{CO}_{2}$ loss by fruit respiration. Oleosynthesis per se is commonly considered as a high energy-consuming process. While the carbon source (photosynthesis) is usually believed to be sufficient for bunch organic-matter production (Corley and Tinker, 2015), estimations of the respiratory cost associated with fruit maturation may indicate the involvement of carbon remobilization from trunk reserve.

\section{Climate change and sex ratio}

The oil palm has a monoecious (also referred to as "temporally dioecious") floral biology as it produces cycles of male and female inflorescences alternately on the same plant. Breeders are at work to increase the sex ratio, which is defined as the number of female inflorescences in relation to the total

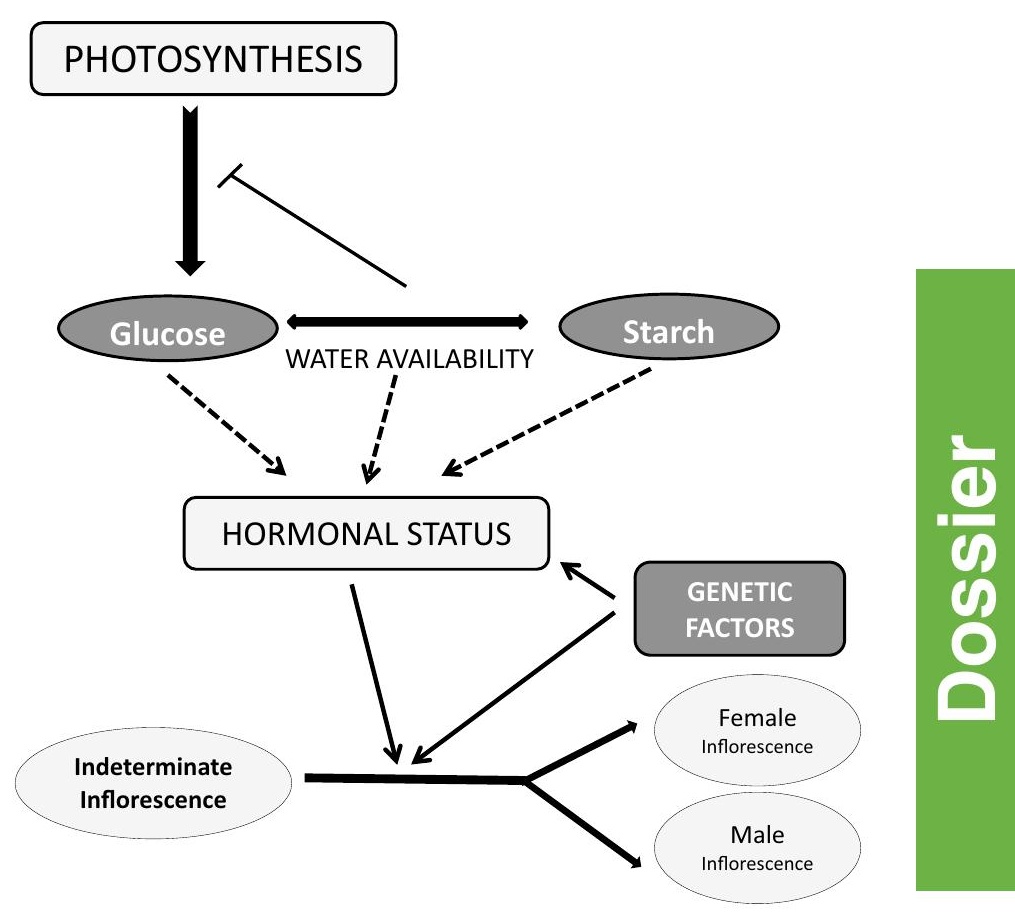

Fig. 3. Putative mode of interaction of factors affecting the sex of inflorescences and targets of molecular studies in the oil palm, adapted from Adam et al. (2011). The schema draws on mostly phenological and physiological data and suggests points of interaction with genetic factors that might be associated with the contrasting behavior of palms of different genotype in the same environmental conditions.

number of inflorescences. For the end user, an ideal oil palm would produce only female inflorescences under any circumstances, if possible!

The sex ratio in the oil palm is known to be governed by both genetic and environmental factors. Adam et al. (2011) examined the current understanding of the process of sex determination in oil palm (Fig. 3). These authors showed that new approaches based on genomics, molecular and biochemical cytology, when combined with field studies should provide a new understanding of the complex processes that govern the determination of sex in the oil palm.

The publication of the oil palm genome sequence by Singh et al. (2013a), followed by research results on the epigenetic determinism of flower structure in the mantled oil palm variants (Jaligot et al., 2014; Ong-Abdullah et al., 2015) have paved the way for the in-depth molecular analysis of sex ratio in the oil palm and the further elucidation of its environment-related determinism.

In addition, the fact that sex ratio in the oil palm is dependent from the genotype raises the possibility of identifying genes determining the sex of inflorescences. Indeed, Somyong et al. $(2014,2015)$ described a putative aldo-keto reductase gene (named EgAKR1) which was revealed as a promising candidate for sex ratio determination via the control of female inflorescence number. More recently, Somyong et al. (2016) identified EgACCO1 (encoding aminocyclopropane carboxylate (ACC) oxidase) at chromosome 10 and EgmiR159a (microRNA 159a) at chromosome 6 
to be the most linked QTL genes or determinants for FFB yield and/or female inflorescence number. Identifying the genetic (or epigenetic) determinisms of sex ratio and their regulatory mechanisms will be a major step towards Markers Assisted Breeding for a higher sex ratio. Additionally, if more sex determination genes controlled by plant hormones are identified, it may possible to reveal a cross-talk of sex determination genes with hormones and environment factors (Fig. 3).

The impact of drought on oil palm has been widely documented (Cochard et al., 2005). Indeed water deficit strongly affects oil palm growth, sex ratio and the rate of aborted female inflorescences, hence yields. Differences in susceptibility to drought were found among planting material from different genetic backgrounds (Maillard et al., 1974) though they were not linked to production potential. When there is no water deficit, oil palm production is spread over the year: the greater the water deficit, the more pronounced is the production peak occurring during the dry period, hence when water requirements are greatest. It would therefore be useful to develop planting material with a wide distribution of yield over the year or with a staggered production peak. Substantial genetic diversity linked to production rhythms has been discovered although production cycles were found to be governed by the same seasonal variations when water deficits were pronounced (Cochard et al., 2005). Lastly, droughtrelated mortality was low in genetic crosses showing a high root density and mechanisms of resistance to cell dehydration have been found (Cornaire et al., 1994). It is worth noticing that such results were obtained in trials which were not specifically designed for the evaluation of drought tolerance, thus trial designs need to be complemented by increasing the genetic diversity to be explored and by designing specific drought-resistance trials aimed at generating one or more selection criteria (Cochard et al., 2005).

\section{Increasing breeding efficiency through genomic selection (GS)}

In response to global population growth and a changing climate, there is an urgent need for plant breeders to work together to improve the selection of parents and offspring in breeding programs, increase the utilization of genetic diversity, group environments to optimize breeding efficiency and accelerate the generation of improved crop varieties (Spindel and McCouch, 2016).

Genomic selection is proving an effective new strategy for increasing breeding efficiency in a wide variety of species including cereals. Recent studies have confirmed that the more correlated phenotypic and environmental data that are used to feed genomics-assisted breeding models, the better the prediction accuracies of the models and the more useful the breeding outcomes. Based on these empirical results, new alliances to share data across genomic selection breeding programs are critical to the rapid development and deployment of new crop varieties.

In perennial crops such as the oil palm, increase in the genetic gain is expected mainly through shortened breeding cycles and increased selection intensity, which requires sufficient GS accuracy in selecting candidates, despite the more often small size of populations involved. Cros et al. (2015a) recently showed that Genomic Selection empirically appeared valuable for reciprocal recurrent selection in oil palm as it could account for family effects and Mendelian sampling terms, despite small populations and low marker density. Cros et al. (2015b) concluded that RRGS (Recurrent Reciprocal Genomic Selection) could increase the annual selection response compared to RRS by decreasing the generation interval and by increasing the selection intensity. RRGS appeared suitable to achieve a long-term increase in the performance for a trait showing heterosis due to the multiplicative interaction between additive and negatively correlated components, such as oil palm bunch production.

\section{With a little help from biotechnologies...}

Molecular approaches and tools have great potential to optimize plant breeding strategies, especially for perennial species (Rival and Jaligot, 2010). In recent years, there has been an exponential increase in molecular resources and methods to identify polymorphisms controlling the characteristics of interest and to explore the mechanisms linking these polymorphisms to phenotypes.

This is particularly the case for the oil palm (Rival and Jaligot, 2010): a sequence of the genome of both E. guineensis and E. oleifera species has been made public (Singh et al., 2013a) and two SNP chips have been recently developed (Kwong et al., 2016; Ting et al., 2016). The genetic determinism of several characters of agronomic interest has been elucidated, such as oil quality (Morcillo et al., 2013), shell thickness (Singh et al., 2013b), fruit colour (Singh et al., 2014) or the mantled somaclonal variation (Jaligot et al., 2014; Ong-Abdullah et al., 2015) together with gene networks at work for oil biosynthesis (Guerin et al., 2016). Furthermore, Tisné et al. (2015) developed a pedigree-based approach using data from ongoing breeding programs to map QTLs. Genetic determinisms contributing to heterotic effects were identified and they provided valuable information for orienting oil palm breeding strategies.

Today, significant efforts are being made in several countries to develop new molecular resources (sequencing, resequencing and chips development) and to explore the genetic basis of complex traits such as yield or resistance to disease. Consequently the availability of such a large amount of resources is deeply modifying oil palm breeding strategies.

Acknowledgements. The author gratefully thanks helpful Cirad colleagues Jean Ollivier, Bernard Dubos, Robert Domaingue and Norbert Billotte for valuable discussions and collective reflexive work which facilitated the production of the present article.

\section{References}

Adam H, Collin M, Richaud F, et al. 2011. Environmental regulation of sex determination in oil palm: current knowledge and insights from other species. Ann Bot 108 (8): 1529-1537.

Barcelos E, Rios S, Cunha RNV, et al. 2015. Oil palm natural diversity and the potential for yield improvement. Front Plant $S c i$ 6: 190. DOI:10.3389/fpls.2015.00190. 
Barfod AS, Hagen M, Borchsenius F. 2011. Twenty-five years of progress in understanding pollination mechanisms in palms (Arecaceae). Ann Botany 108 (8): 1503-1516. DOI:10.1093/aob/ mcr192

Carron MP, Auriac Q, Snoeck D, et al. 2015. Spatial heterogeneity of soil quality around mature oil palms receiving mineral fertilization. Eur J Soil Biol 66: 24-31.

Cochard B, Amblard P, Durand-Gasselin T. 2005. Oil palm genetic improvement and sustainable development. OCL 12 (2): 141-147. DOI:10.1051/ocl.2005.0141.

Corley RHV, Tinker PB. 2015. The Oil Palm, 5th ed. Chichester, UK: John Wiley \& Sons, Ltd. DOI: 10.1002/9781118953297.

Cornaire B, Daniel C, Zuily-Fodil Y, Lamade E. 1994. Le comportement du palmier sous stress hydrique. Données du problème, premiers résultats et voies de recherche. Oléagineux 49: 1-12.

Cros D, Denis M, Sánchez L, et al. 2015a. Genomic selection prediction accuracy in a perennial crop: case study of oil palm (Elaeis guineensis Jacq.). Theor Appl Genet 128: 397. DOI:10.1007/s00122-014-2439-z.

Cros D, Denis M, Bouvet JM, Sánchez L. 2015b. Long-term genomic selection for heterosis without dominance in multiplicative traits: case study of bunch production in oil palm. BMC Genomics 16: 651. DOI:10.1186/s12864-015-1866-9.

Guerin C, Joët T, Serret J, et al. 2016. Gene coexpression network analysis of oil biosynthesis in an interspecific backcross of oil palm. Plant $J$ 87: 423-441. DOI:10.1111/tpj.13208.

Hospes O, Kroeze C, Oosterveer P, Schouten G, Slingerland M. 2017. New generation of knowledge: Towards an inter- and transdisciplinary framework for sustainable pathways of palm oil production. NJAS Wagen J Life Sci, in press.

Jaligot E, Hooi WY, Debladis E, et al. 2014. DNA methylation and expression of the EgDEF1 gene and neighboring retrotransposons in mantled somaclonal variants of oil palm. PLOS ONE 9 (3): e91896.

Kwong QB, Teh CK, Ong AL, et al. 2016. Development and validation of a high density SNP genotyping array for African oil palm. Mol Plant 9 (8): 1132-1141. DOI:10.1016/j.molp.2016.04.010.

Lamade E, Tcherkez G, Darlan $\mathrm{NH}$, et al. 2016. Natural ${ }^{13} \mathrm{C}$ distribution in oil palm (Elaeis guineensis Jacq.) and consequences for allocation pattern. Plant Cell Environ 39: 199-212. DOI: $10.1111 /$ pce. 12606 .

Maillard G, Daniel C, Ochs R. 1974. Analyse des effets de la sécheresse sur le palmier à huile. Oléagineux 29: 8-9.

Mariau D, Houssou M, Lecoustre R, Ndigui B. 1991. Oil palm pollinating insects and fruitset rates in West Africa. Oléagineux 46 (2): 43-51.

Morcillo F, Cros D, Billotte N, et al. 2013. Improving palm oil quality through identification and mapping of the lipase gene causing oil deterioration. Nat Commun 4 (2160): 1-8.

Ollivier J, Flori A, Cochard B, Amblard P, Turnbull N, Syahputra I, Suryana E, Lubis Z, Surya E, Sihombing E, Durand Gasselin T. 2016. Genetic variation in nutrient uptake and nutrient use efficiency of oil palm. $J$ Plant Nutr. DOI:10.1080/ 01904167.2016.1262415.
Ong-Abdullah M, Ordway JM, Jiang N, et al. 2015. Loss of Karma transposon methylation underlies the mantled somaclonal variant of oil palm. Nature 525 (7570): 533-537.

Pardon L, Bessou C, Nelson PN, et al. 2016. Key unknowns in nitrogen budget for oil palm plantations: a review. Agron Sustain Dev 36: 20. DOI:10.1007/s13593-016-0353-2.

Paterson RRM, Sariah M, Lima N. 2013. How will climate change affect oil palm fungal diseases? Crop Protect 46: 113-120. DOI:10.1016/j.cropro.2012.12.023.

Perez RPA, Pallas B, Le Moguédec G, et al. 2016. Integrating mixedeffect models into an architectural plant model to simulate interand intra-progeny variability: a case study on oil palm (Elaeis guineensis Jacq.). J Exp Bot 67 (15): 4507-4521. DOI:10.1093/ jxb/erw203.

Pilbeam DJ. 2015. Breeding crops for improved mineral nutrition under climate change conditions. J Exp Bot 66 (12): 3511-3521. DOI:10.1093/jxb/eru539.

Rival A. 2013. The oil palm: challenges and questions to research. OCL 20 (3): 133-142. DOI:10.1684/ocl.2013.0506.

Rival A, Jaligot E. 2010. Oil palm biotechnologies are definitely out of infancy. OCL 17 (6): 368-374. DOI:10.1051/ocl.2010.0341.

Rival A, Levang P. 2014. Palms of controversy : oil palm and development challenges. Bogor, Indonesia: Cifor. ISBN 978-6021504-41-3.

Rival A, Montet D, Pioch D. 2016. Certification, labelling and traceability of palm oil: can we build confidence from trustworthy standards? OCL 23 (6): D609. DOI:10.1051/ocl/2016042.

Singh R, Ong-Abdullah M, Low ETL, et al. 2013a. Oil palm genome sequence reveals divergence of interfertile species in Old and New worlds. Nature 500: 335-339. DOI:10.1038/nature12309.

Singh R, Low ETL, Ooi LCL, et al. 2013b. The oil palm SHELL gene controls oil yield and encodes a homologue of SEEDSTICK. Nature 500 (7462): 340-344.

Singh R, Low ETL, Ooi LCL, et al. 2014. The oil palm VIRESCENS gene controls fruit colour and encodes a R2R3-MYB. Nat Commun 5 (4116): 1-8.

Somyong S, Poopear S, Jomchai N, et al. 2015. The AKR gene family and modifying sex ratios in palms through abiotic stress responsiveness. Funct Integr Genomics 15: 349. DOI:10.1007/ s10142-014-0423-y.

Somyong S, Poopear S, Sunner SK, et al. 2016. ACC oxidase and miRNA 159a, and their involvement in fresh fruit bunch yield (FFB) via sex ratio determination in oil palm. Mol Genet Genomics 291 (3): 1-15.

Spindel JE, McCouch SR. 2016. When more is better: how data sharing would accelerate genomic selection of crop plants. New Phytol 212: 814-826. DOI:10.1111/nph.14174.

Ting N-C, Yaakub Z, Kamaruddin K, et al. 2016. Fine-mapping and cross-validation of QTLs linked to fatty acid composition in multiple independent interspecific crosses of oil palm. BMC Genomics 17: 289. DOI:10.1186/s12864-016-2607-4.

Tisné S, Denis M, Cros D, et al. 2015. Mixed model approach for IBD-based QTL mapping in a complex oil palm pedigree. $B M C$ Genomics 16 (1): 1.

Cite this article as: Rival A. 2017. Breeding the oil palm (Elaeis guineensis Jacq.) for climate change. OCL, 2017, $24(1)$ D107. 